\title{
Relationship between Nighttime Leisure Behaviour and Urban Park Setting in Shah Alam
}

\author{
Mohd Riduan Ngesan¹, Hafazah Abdul Karim², Syed Sobri Syed Zubir ${ }^{3}$ \\ ${ }^{1}$ Centre for Environment-Behaviour Studies, ${ }^{2}$ Centre for Town and Regional Planning Studies ${ }^{3}$ Centre for \\ Architecture Studies, Faculty of Architecture, Planning \& Surveying, \\ Universiti Teknologi MARA, Shah Alam 40450, Malaysia \\ nightcityconcept@gmail.com
}

\begin{abstract}
Public parks play a vital role in the social life of urban communities. The purpose of this paper is to show the social behaviour and activities of a community during nighttime in outdoor spaces exclusively in public urban park in Shah Alam. However, literature reviews regarding nighttime social behaviour and activities of urban community are limited. Improved understanding of relation between community activity and urban park setting could be used to influence the development of public park design, to create nighttime urban outdoor environments more conducive for community leisure activity.
\end{abstract}

Keywords: Human behaviour; leisure; nighttime activities; public park

eISSN 2398-4295 @ 2018. The Authors. Published for AMER ABRA CE-Bs by e-International Publishing House, Ltd., UK. This is an open-access article under the CC BY-NC-ND license (http://creativecommons.org/licenses/bync-nd/4.0/). Peer-review under responsibility of AMER (Association of Malaysian Environment-Behaviour Researchers), ABRA (Association of Behavioural Researchers on Asians) and cE-Bs (Centre for EnvironmentBehaviour Studies), Faculty of Architecture, Planning \& Surveying, Universiti Teknologi MARA, Malaysia.

DOI: http://dx.doi.org/10.21834/ajbes.v3i9.56 


\subsection{Introduction}

Communities living in urban areas used the outdoor public park as a place for social and leisure activities with their families, friends and others. However, the hot climate during the day due to the effect of global warming discouraged human activities in urban outdoor spaces. Furthermore the busy lifestyle of urbanites also affects the lack of time for leisure and recreation activities in urban outdoor spaces. These constraints have changed the behavioral patterns of the urban communities where people prefer to carry out their leisure activities in outdoor public-park after the sun has set. Yet the current planning and designed of outdoor public realm is not accommodative for community nighttime leisure and recreation (Ngesan and Karim 2012). Nowadays, most of the community's activities during nighttime only take place indoors- in cinema, restaurants, shopping complexes, etc. The use of indoor rather than open and green outdoor spaces in leisure time has led to more passive urbanite lifestyle. People neglect the fact that physically active lifestyle with outdoor green environment are important in term of physical and mental health. Cheshmehzangi (2012) argues that, public realm could appear in many ways, and that by itself, have no definite identity or character of place. In this respect, public realm does not have a certain identity but rather is fulfilled with several changing identities influenced by content (i.e. person or object) and context (i.e. culture or environment) where content is the inherent value (Relph, 1976). At this juncture, the study of urban community behaviour and activities during nighttime at outdoor public park seemed to be warranted and in line with the Malaysian Economic Transformation Programme, under Entry Point Project 6 (EPP6); to ensure every resident in Greater Kuala Lumpur/ Klang Vally benefits from the green space. This programme also aims to improve cities liveability by creating more comfortable spaces for leisure and recreational activities; and most importantly to create a sustainable environment. For this particular research, the city of Shah Alam is chosen as the case study. It is the state capital of Selangor and situated within the conurbation of the Klang Valley and is located around twenty-five kilometers west of the country's capital city, Kuala Lumpur. Since independence in 1957, Shah Alam can be considered as the first planned city that incorporated the green and community concept for urban development. In 2000, Shah Alam has been declared and conferred the city status and has its own Municipal City Council.

\subsection{Literature Review}

\subsection{The concept of place and behavior}

The mutual relationship between space and human can be considered as sense of place or spirituality of place. Cheshmehzangi (2012) mentions that, social behaviorism of a place is either controlled by design or developed with it. Therefore, environmental perception of any place has a mutual relationship with its social behaviorism termed as 'socio-environmental values' and 'spatial inter-relations'. According to Walmsley (1988), the 'environment as perceived rather than the real world which influences behaviors'. Certain characteristics and urban formations are important aspects of how environment can control or/and enhance the 
social behaviors. Hague and Jenkins (2005) argues that identity of a place is a matter of socio-environmental values and spatial inter-relations with which place also aims to develop as well as becoming developed itself. Therefore, it is not only the place that needs to be studied but also the human himself and how he behaves and relates to his environment.

\subsection{The concept of place and time}

Cheshmehzangi (2012) elucidates that actions taken place within the environment are outcomes of the urban system, which could modify qualities and adjust inner character development and future inputs within public place. Nighttime activities in public-park are part leisure and part recreation that has become an urban trend. Hague and Jenkins (2005) describes that the understanding of place requires various techniques and investigations based on three factors namely space, nature and time. Therefore, Relph (1976) explicates that place can have multiple identities to one person as well as to the whole society, therefore the possibility of having different answers and results will depend on different context that are self-associated with different times.

\subsection{The concept of social behavior and climate}

Knez (2005) argues that climate is one of the attributes that brings meaning to the place of people. This ecological variable, a physical parameter of a place, plays an important role in everyday life. It has impact on individual, social and economy. Moreover, peoples' perceptions towards the beautiful of place are different due to factors of microclimatic condition such as sunlight and wind. These and other microclimatic parameter such as temperature and humidity may also influence our perception towards comfort. According to Emmanuel (2005), the Urban Heat Island (UHI) at nighttime in an urban center is highly correlated with urban tree cover characteristic. He also argues that significant nighttime cooling could be achieved by increasing the Sky View Factor (SKV) and by improving the thermal properties in the area. During nighttime, the thermal properties such as green surface in the open area with less trees cover are more cooling with other urban outdoor spaces due to the increasing of the Sky View Factor that realize the Urban Heat Island.

\subsection{The concept of urban well-being}

The quality of life in a city is not only related to the quantity of collective resources and services available in an urban area, but also to the opportunities and constraints of people to use such resources (Nuvolati, 2010). He also argues that the transformation and distribution of abundant urban resources into real quality of life becomes more complicated, especially in large cities where many different urban populations such as residents, city users and tourists are concentrated. Currently, many nightlife activities are focus on city users and tourists such as pubs, bars, nightclubs, concerts and others that disturb the urban community during nighttime (Ngesan and Karim, 2011). The urban well-being is considered as one of the potential for urban community to use the urban resources at nighttime through cultural activities. This can be archived from the generation of outdoor public park for community activities not only during the day but continues until nighttime. Meanwhile, nighttime activities 
should have time limitations to ensure the normal circadian rhythm cycle for living being that requires the human body to sleep and rest (Kolmos, 2007).

\subsection{The usage of public park at night}

According to Project for Public Space (2005), the type of use in parks have changed over the course of the day progresses; from a more quiet activities during the day to a more socializing activities in the evening and night. Moreover, the users seem to distribute throughout the park during the day; while evenings until night, the area become more alive with social and leisure activities which focused on the center of the park. By looking at the aspect of safety and security, park users rarely noted safety as a concern. Most people felt the presence of "undesirables" and drug dealers, but the vibrant and heavily use space around them tends to marginalize this negative activity, or at least make people feel relatively comfortable. As evidence, small children can be found in the Washington Park, with their parents, late at night (9pm) near the fountain and even in unlit playgrounds. Akin to this, Ozcan (2006) states that compared to adults, children are known to be more sensitive in their perception of the physical environment; hence it has a greater effect on the way they conduct themselves. Moreover, the safety of the place also can be seen by the existence groups of women. In our modern societies light plays an increasing role in promoting leisure activities, well-being and the most significant is that artificial light gives people the perception of night territory appropriation/ domination (Alves, 2009). Zaki and Ngesan (2011) postulate that the agglomeration of nighttime activity is able to created different activity to attract people. They also confirm that the creative arrangement of urban components can increase the urbanites movement in urban outdoor spaces. Meanwhile, nighttime is the period where people must be resting and sleeping, respecting their biological needs.

\subsection{Methodology}

The purpose of this paper was to investigate the influence of spatiality on the community activity and behavior at the two public urban parks during nighttime. Initially, Shah Alam has been chosen as a study area due to its subdued urban nature: - a well provided community facilities; and the lack of nighttime commercial and entertainment centres. For the behavioral mapping survey, this study will use place-centered mapping technique to observe how people use the space. The observation survey involved natural unobtrusive observation and video recording of group behaviour at urban park during nighttime. The behavioral mappings have to be included in order to identify the spatial choice and location in the urban park. The time sampling is taken for 10 minutes with time interval for 20 minutes for each study area. Earlier observations have been done to determine the use of urban park at night as a time-frame and to verify the observation form as checklist for the main survey; it was found that the urban park beginning to be crowded starting from 7.30pm until 9.30pm. The researcher also used some variables in the System for Observing Play and Active Recreation in Communities (SOPARC) as part of the component in the analysis stage. SOPARC was designed to obtain direct information on community park use, including their users. It provides an assessment 
of park users' physical activity levels, gender, activity types, and estimated age groupings (McKenzie, 2006).

\subsection{Findings and Analysis}

The survey illustrates that the average users of urban park at nighttime during the observation days are 662 people. This shows that the night-time leisure activity has become an urban trend (Ngesan and Karim, 2012). Meanwhile, the user in study area of Padang $A$ (362 people) is higher compared to the Padang $B$ (302 people) even though the area of Padang $A$ (1.79 hectare) is smaller than Padang $B$ (2.52 hectare). This has a relation with the location of the study area where Padang $A$ is located in the middle of iconic buildings such as Shah Alam Gallery, Auditorium, Blue Wave Hotel, Blue Mosque Shah Alam and many others, which give an interesting lighting silhouette at night rather than Padang $B$ which is located beside a main road junction. Besides that, the differences of ground cover characteristic in the study area that affect the Urban Heat Island (Emmanuel, 2005), where Padang $A$ is covered fully by grass and Padang $B$ is covered with a mixed of grass and sand surface has influence the site preferences to do leisure at night. Since the influence of the physical environment, climate and time upon human behavior had been well documented in the literature review, this paper posited that the exhibition of more appropriate behaviors by the human during nighttime was the outcome of a better outdoor space design.

\subsection{The use of urban park at nighttime by age group and gender}

The highest numbers of percentage in the age groups are adults totaling 81.90 percent (Refer Table 1.).

Table 1. The use of urban park at nighttime by age group and gender

\begin{tabular}{|c|c|c|c|c|c|c|c|c|c|c|}
\hline \multirow[t]{2}{*}{ Location } & \multicolumn{2}{|c|}{$\begin{array}{l}\text { Senior } \\
60 \text { year olds above } \\
\text { (\%) }\end{array}$} & \multicolumn{2}{|c|}{$\begin{array}{l}\text { Adults } \\
20-59 \text { year olds } \\
\text { (\%) }\end{array}$} & \multicolumn{2}{|c|}{$\begin{array}{l}\text { Teenagers } \\
13-19 \text { year olds } \\
\text { (\%) }\end{array}$} & \multicolumn{2}{|c|}{$\begin{array}{l}\text { Children } \\
0-12 \text { year olds } \\
(\%)\end{array}$} & \multicolumn{2}{|c|}{$\begin{array}{l}\text { Total } \\
\text { age group and } \\
\text { gender }(\%)\end{array}$} \\
\hline & Male & Female & Male & Female & Male & Female & Male & Female & Male & Female \\
\hline Padang A & 0.20 & 0.41 & 23.17 & 21.21 & 1.36 & 1.05 & 3.27 & 3.67 & 28.00 & 26.34 \\
\hline Padang $B$ & 0.00 & 0.20 & 20.39 & 17.13 & 2.11 & 1.36 & 2.96 & 1.51 & 25.46 & 20.20 \\
\hline Subtotal by gender & 0.20 & 0.61 & 43.56 & 38.34 & 3.47 & 2.41 & 6.23 & 5.18 & 53.46 & 46.54 \\
\hline Subtotal by age group & 0.81 & & 81.90 & & 5.88 & & 11.41 & & 100.00 & \\
\hline
\end{tabular}

The findings reveal that although the adults have to working during the day, these age groups of people are able to spend time to do leisure activities with their friends and families in outdoor spaces at nighttime. Moreover, the slightly different percentage of gender between males (53.46 percent) and females (46.54 percent) highlight the existence of families and group of friends. It supports the findings from the observation survey that the majority of user is the groups of family and friends. Female makes-up 46.54 percent that indicates the community of Shah Alam perceived urban park as a safe place at nighttime. Hence, the existence of children, which is 11.41 percent, shows that the place is safe. Children are known to be more sensitive in their perception of the physical environment; hence it has a greater effect on the way they conduct themselves. Besides that teenagers, which is 5.88 
percent also reveals that, nighttime activities in urban parks are attractive to this age group. This can reduce unwarranted juvenile activities. Referring to Table 1. the park users comprised all age group. These illustrate varieties of users in urban park at nighttime which forms the cordial community social relationship.

\subsection{The users position in urban park at nighttime}

Table 2. shows Padang $A$ having a higher percentage in all the positions behavior in urban park namely sitting on grass (32.63 percent), sitting on bench (8.16 percent) and lying on grass (1.51 percent) except for standing (12.08 percent) compare to Padang $B$ (14.80 percent). This position is influenced by the ground cover characteristic, which is grass. As mentioned earlier, Padang $A$ is covered by grass while Padang $B$ is covered with mixed grass and sand (Refer Fig. 1.). Since the physical character place of study areas are without any playground facilities, the users' prefer to use the ground surface as the place for their activities. Moreover, the position behavior of sitting on grass is 56.19 percent is higher compared to the position behavior sitting on benches, which is 14.51 percent. These studies reveal that the surface materials for nighttime leisure activity in Shah Alam are able to influence the position behavior of users. The position of lying on grass which is 2.42 percent also show that the minimum light pollution during nighttime in the study area due to the clear visibility of moon and stars; can be enjoyed by urbanites in Shah Alam.

Table 2. The users position in urban park at nighttime

\begin{tabular}{|c|c|c|c|c|}
\hline $\begin{array}{l}\text { Padang } A \\
\text { Pocation } A \\
\text { Padang } B\end{array}$ & $\begin{array}{l}8.16 \\
\text { Sittigy on bench }(\%)\end{array}$ & $\begin{array}{l}32.63 \\
\text { Sittjingon grass (\%) }\end{array}$ & $\begin{array}{l}12.08 \\
\text { Standing (\%) }\end{array}$ & $\begin{array}{l}1.51 \\
\text { L pi.p. on grass (\%) }\end{array}$ \\
\hline Subtotal & 14.51 & 56.19 & 26.88 & 2.42 \\
\hline Total & 100.00 & & & \\
\hline
\end{tabular}

\subsection{The physical activity in urban park at nighttime}

The analyses of physical activity/behavior are based on variable in the SOPARC. There are three physical activity levels namely sedentary, walking and vigorous (McKenzie, 2006). Sedentary refers to individual's behavior of lying, sitting or standing in place. Moderate refers to sports, recreation and fitness, while vigorous refers to individual's behavior engaging at an intensity level more vigorous than an ordinary walk. This activity will increase human heart rate causing them to sweat. Based on the observation survey, the activities of urbanites in urban park during nighttime have been listed and categorized into the three levels. Table 3 . illustrates that the highest level activity is sedentary $(72.37 \%)$ while the highest of the total physical activity is eating and picnics (42.00\%). This study reveals that the preference activity by urban community during nighttime in urban park is sedentary. 
Table 3. The physical activity in urban park at nighttime

\begin{tabular}{|c|c|c|c|c|c|c|c|c|c|c|}
\hline \multirow[t]{3}{*}{ Location } & & & & & & & & & & \\
\hline & \multicolumn{3}{|c|}{ Sedentary (\%) } & \multirow[b]{2}{*}{ 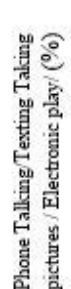 } & \multirow[b]{2}{*}{ 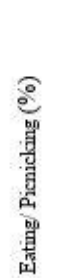 } & \multirow[b]{2}{*}{ 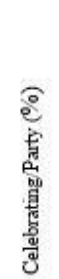 } & \multicolumn{2}{|c|}{ Moderate (\%) } & \multicolumn{2}{|c|}{ Vigorous (\%) } \\
\hline & 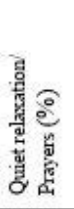 & 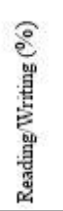 & 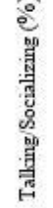 & & & & 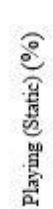 & 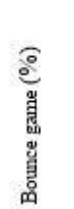 & 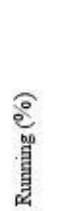 & 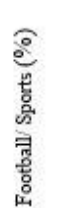 \\
\hline & 2.27 & & 3.93 & & 23.87 & 4.68 & & 3.02 & & 4.83 \\
\hline \multirow{2}{*}{ Padang $B$} & & 1.06 & & 5.29 & & & 1.96 & & 3.47 & \\
\hline & 1.81 & & 2.57 & & 18.13 & 3.78 & & 2.42 & & 7.55 \\
\hline \multirow{2}{*}{ Subtotal by types activity } & & 0.45 & & 4.53 & & & 1.51 & & 2.87 & \\
\hline & 4.08 & & 6.50 & & 42.00 & 8.46 & & 5.44 & & 12.38 \\
\hline \multirow{3}{*}{ Subtotal by level of activity } & & 1.51 & & 9.82 & & & 3.47 & & 6.34 & \\
\hline & 72.37 & & & & & & 8.91 & & 18.72 & \\
\hline & 100.00 & & & & & & & & & \\
\hline
\end{tabular}

Fig. 1. shows the distribution of activities in the urban park during nighttime. The sedentary activities in Padang $A$ are scattered in all areas, while in Padang $B$ are located at the edges of the study area. The moderate activity areas are identified to be located close with sedentary activity for both areas. The vigorous activity are tend to be scattered in Padang $A$ and located at the center of the area in Padang B. Moreover, Padang A are more condensate compared to Padang $B$ due to the different ground cover material and building activity in the surrounding area. Besides, Padang $A$ are also more lighting up rather than Padang $B$ since the light is factors that contributes towards the sense of safety and security.

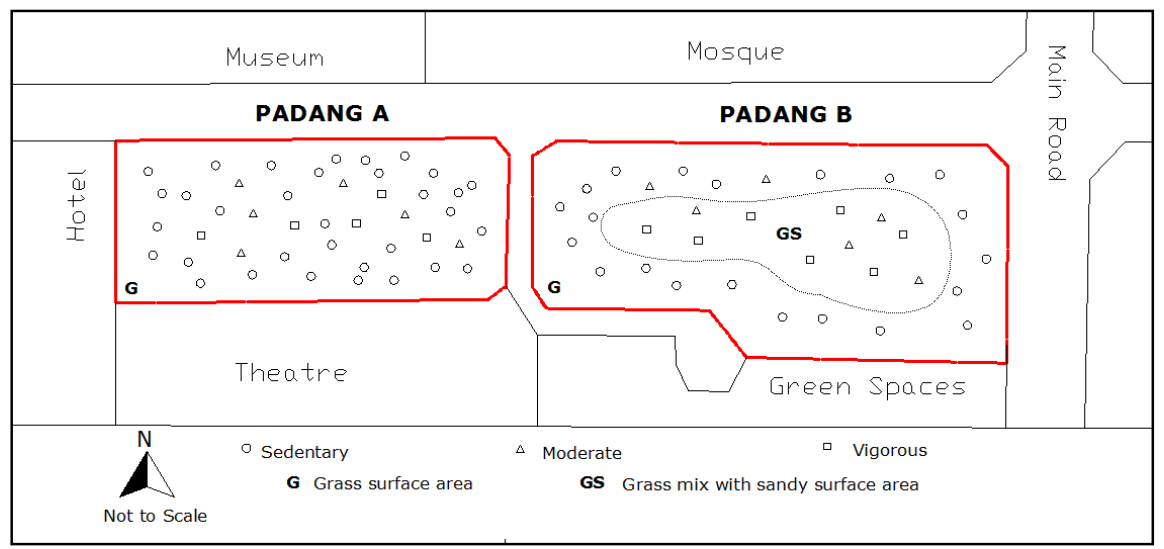

Fig. 1. Physical activity behavior map 


\subsection{Conclusion}

Overall, this research founds that people who are living in the area of the case study significantly use the urban public park for leisure and recreational activities during nighttime. Through the survey conducted at the area, the users were ranging from different age groups and genders. This indicates that urban public park which efficiently designed to meet urban livability could encourage the urban social relations among the community. The elements of livable urban public park such as the lighting factor, ground material characteristic, park facilities and the surrounding building uses activities also contribute to the preferences of place for leisure and recreational activities during nighttime in outdoor spaces. Behavioral mapping provides a method for objectively measuring relationship between human activities and urban park during nighttime. The slight differences in the behavioral patterns observed with regards to physical activity within the confinement of the different urban park settings should also be noted. As the analysis of this phenomenon is beyond the scope of this paper, it could be investigated further in future studies.

\section{Acknowledgement}

The writers would like to acknowledge Universiti Teknologi MARA (UiTM) and to Shah Alam City Council (MBSA) for their endless assistance given during the course of carrying out the study. This study was funded by Research Intensive Faculty (Grant 600-RMI/DANA 5/3/RIF 264/2012), provided by Research Management Institute, Universiti Teknologi MARA Shah Alam, Malaysia.

\section{References}

Alves, T. (2009), Geografia da noite. Centro de estudos geográficos, Universidade de Lisboa.

Cheshmehzangi, A. (2012). Identity and public realm. Procedia Social and Behavioural Sciences, 50, 307-317.

Emmanuel, M.R. (2005). An urban approach to climate sensitive design - Strategies for the tropics. Spon Press Taylor \& Francis Group.

Hague, C. \& Jenkins, P. (2005). Place identity, planning and participation, London: Routledge.

Knez, I. (2005). Attachment and identity as related to a place and its perceived climate. Journal of environmental psychology, 25, 207-218.

Kolmos, E. and S.J. Davis (2007). Circadian rhythms: Rho-related signals in time-specific light perception. Current Biology, 17(18), 808-810.

McKenzie, T. L., Cohen, D. A., Sehgal, A., Williamson, S., \& Golinelli, D. (2006). System for Observing Play and Leisure Activity in Communities (SOPARC): Reliability and feasibility measures. Journal of Physical Activity and Health, 1, 203-217.

Ngesan M.R. \& Karim, H.A. (2011). Impact of night commercial activities towards quality of life of urban residents. Procedia - Social and Behavioral Sciences, 35, 546 - 555. 
Ngesan, M.R., et.al. Asian Journal of Behavioural Studies (AjBeS), 3(9) Jan / Feb 2018 (p. 173-181)

Ngesan M.R. \& Karim, H.A. (2012). Night time social behavior in urban outdoor spaces of Shah Alam. ProcediaSocial and Behavioural Sciences, 50, $959-968$.

Nuvolati, G. (2010). City lights. The world book of happiness (pp. 110-113). Pageon. Page One publishing Pte Ltd.

Ozcan, H. (2006). Healing design: A holistic approach to social interaction in pediatric intensive care units in the United States and Turkey, PhD Dissertation,Texas A \& M University, USA.

Project for Public Space (2005). Washington Square Park. A user analysis and place performance evaluation. New York.

Relph, E. (1976). Place and placelessness, London: Pion Limited.

Walmsley, D. J. (1988). Urban living: The individual in the city, Harlow: Longman Scientific and Technical

Zaki, S.A \& Ngesan, M.R. (2011). A future town redesigned - How movement pattern is affected with the concept of night city. Procedia - Social and Behavioral Sciences, 36, $204-210$. 